\title{
Implementing evidence-based guidelines for nutrition support in acute stroke
}

This work forms part of the South Thames Evidence-Based Practice (STEP) Project funded in 1996 by what was then South Thames Research and Development Directorate of the UK Department of Health. STEP was a major multidisciplinary initiative supported by collaborative partnerships between university departments and National Health Service (NHS) Trusts with the aim of evaluating implementation of research evidence in a variety of settings. External evaluation was done by King's College.

A range of topics was identified with substantial evidence bases. South London Trusts were invited to participate where topics matched their service priorities. 9 projects were sited in 8 Trust locations and focused on leg ulcer management, pressure area care, continence, breast feeding, family centred care in schizophrenia, discharge planning, nutrition (2 projects), and rehabilitation management in stroke. Each project reported separately, and separate academic teams provided internal and external overview evaluation reports. ${ }^{1-2}$ The following is a description of one of these projects, which focused on nutrition for patients with acute stroke.

\section{Nutrition in acute stroke}

Stroke is a major cause of mortality, morbidity, and enduring disability in industrialised countries, producing a range of problems that influence eating and dietary intake. ${ }^{3-4}$ Nutrition in hospital affects progress and response to treatment, morbidity, mortality, and unplanned readmission. ${ }^{5}$ On admission, $16-31 \%$ of patients with stroke have indices of malnutrition, ${ }^{6-7}$ and the rate increases thereafter. Almost 50\% of patients admitted to rehabilitation units are affected, ${ }^{8-9}$ with multiple nutritional risk factors conferring increased vulnerability. Malnutrition has been linked with increased risk of death and dependency after stroke. ${ }^{9-10}$ To address these concerns, the STEP Project for nutrition support in acute stroke aimed to develop, implement, and evaluate evidence-based multiprofessional guidelines.

\section{The guidelines and their underpinning evidence}

The academic and clinical managers at the institution of the project agreed on the outline project remit, which encompassed screening, assessment, and management of all aspects of nutritional support for patients with stroke. With the appointment of the project coordinator (LP), a project team was established with representatives of all professional groups involved with patients with stroke. User representation was considered, but a suitable volunteer could not be found in the time available. The project coordinator developed and implemented a standardised systematic search and review process ${ }^{11}$ for a range of topics on nutritional support. 2 nutrition focused projects were done at 2 sites by 2 coordinators (a nurse and a dietitian), and data were independently extracted and compared. ${ }^{12}$ Studies were evaluated for methodological quality using recognised criteria based on research design. ${ }^{11}$

The project team collaboratively reviewed the extracted data and identified resultant recommendations that were categorised according to type and strength of underpinning evidence, ${ }^{13}$ which ranged from expert consensus to clinical trials. 24 guidelines were developed and included recommendations for screening for nutritional risk, dysphagia, and other impairments that affect eating (table 1); timing and processes for appropriate referral; and nutritional management, including dietary supplementation, modified diets, and artificial nutrition support. 2 guidelines were supported in some part by at least 1 randomised controlled trial (grade A recommendation); 16 were supported by non-randomised trial data (grade B); and 6 were solely supported by expert consensus (grade C), in some instances derived from local "experts" ${ }^{13}$ For example, it was recommended that patients have a maximum of 5 days with nothing orally before nutrition support decision making was initiated.

Evidence was also sought to inform the dissemination, implementation, and change management strategies. ${ }^{14}$ Table 1 Guideline recommendations for screening and assessment of
dysphagia*

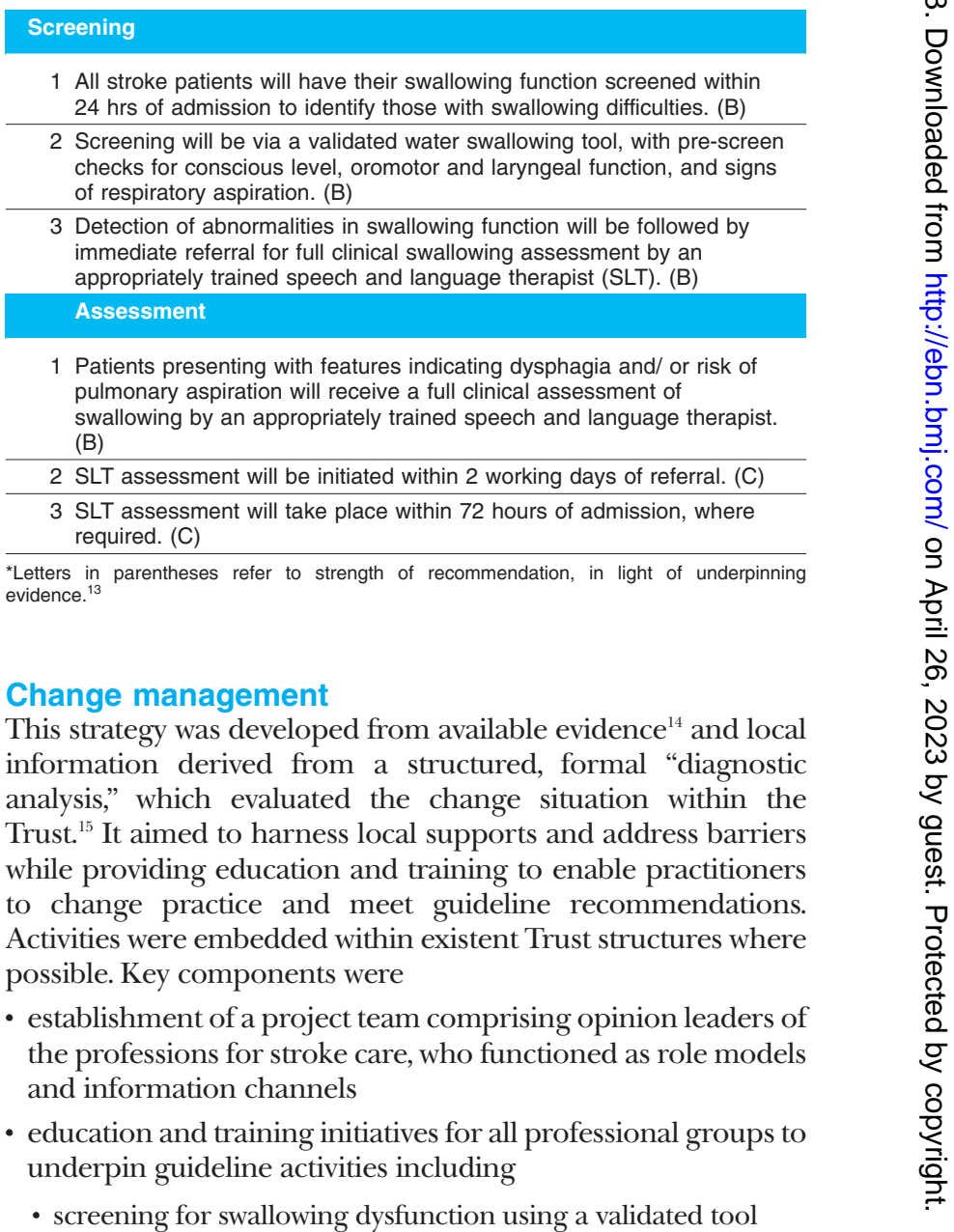


- early initiation of nutritional support decision making, referrals, and management

- effective artificial nutrition support (modified diets and tube feeding)

- multidisciplinary development of evidence-based, user friendly guidelines (single page and booklet formats)

- facilitation, coordination, reinforcement, and role modelling by a full time project coordinator

- extensive communication at all levels, for guiding and informing project activities and for progress reporting and updating: individual sessions with clinicians; ward/unit meetings; existing groups (eg, Sisters' meetings, Trust Board); memos and news sheets; and local newspaper and cable television

- presentation, dissemination, and discussion of guidelines with all relevant groups

- use of outside experts for discussion and "selling" of new practices. This addressed specific concerns, such as effects of inappropriate nutritional support on quality of life

- use of existing groups and structures (eg, pressure damage link nurses, the Scope of Professional Practice In-Service Training programme, and continuing medical education)

- high level managerial and academic support.

Implementation involved changes in practice and professional roles, such as the introduction of validated screening tools for nutritional risk and dysphagia for use by nurses (both tools) and medical staff (dysphagia). Appropriately trained nursing staff adopted roles that were previously exclusively medical roles (eg screening swallowing function on admission and contacting speech and language therapists [SLTs] for clinical assessment; placement of fine bore feeding tubes with placement checked via gastric aspirate where possible [ie, $\mathrm{x}$ ray no longer mandatory]). Main conclusions derived from the "diagnostic analysis" are outlined in table $2 .{ }^{16}$

Table 2 Main conclusions of the "diagnostic analysis" in relation to change management ${ }^{* 16}$

\section{Levers and supports}

- strong areas of expertise (eg, SLT Dysphagia Service, SRW)

- general support for project aims at all levels of the Trust

- some specific concerns about project issues, which key individuals were keen to address

- enthusiastic support from key individuals, including finding additional resources

- a strong managerial structure and ethos

- existing structures, especially CPD programmes, into which to dovetail project activities

Barriers and hindrances

- time and resource constraints

- a strong managerial structure and ethos

- communication channels-could be highly informal or inflexible

- varied knowledge base; a tendency to rely upon local "experts"

- lack of precedent for this type of project in the Trust

${ }^{*} \mathrm{SLT}=$ speech and language therapist. SRW $=$ stroke and rehabilitation ward. $\mathrm{CPD}=$ continuing professional development.

\section{Baseline and post-implementation audit methods}

2 groups of 200 patients consecutively admitted with a clinical diagnosis of acute stroke were assessed (1 group admitted before guideline implementation and 1 group admitted after). Patients were admitted to 11 medical care of the elderly wards, and some were transferred later to a stroke and rehabilitation ward (SRW). 14 consultants and their teams, dietitians, SLTs, and generic (on wards) and neurological (on SRW) physiotherapists and occupational therapists participated in patient care.
The project coordinator reviewed multiprofessional documentation and extracted stroke and nutrition related data. Interrater reliability of data extraction was checked with an independent researcher $(\mathrm{kappa}=0.88)$. The project coordinator used the National Institutes of Health Stroke Severity Scale $(\text { NIHSSS })^{17}$ to assess stroke severity. Outcomes of interest were

- screening and referral for full clinical assessment of swallowing function

- screening for nutritional risk and monitoring of nutritional status

- referral for occupational therapy and physiotherapy

- initiation of nutrition support decision making and nutrition support management

- patient outcomes, including functional recovery, length of stay, changes in anthropometric indices between admission and discharge, recorded medical complications, mortality, and discharge destination

Convenience subsamples of patients and carers (where appropriate) were interviewed at discharge $(n=49$ and $n=46$, respectively). Mealtime and nutritional experiences were explored using open ended questions. A convenience sample of meal situations (sampling all wards and meals on both week days and weekends) was observed using a structured observation proforma ${ }^{18}(\mathrm{n}=20,10$ meals observed).

\section{Results}

Guideline implementation activities proceeded generally as planned. Minor modifications were made as required. The 2 patient groups did not differ for demographic indices, stroke severity (median NIHSSS scores $7 v 8$ ), or nutritional characteristics. Patients with stroke comprised $33 \%$ and $22 \%$ of patients observed during mealtimes, and $67 \%$ and $69 \%$ needed help eating, were fed, or were tube fed (table 3). Details of stroke related eating disabilities are reported elsewhere. ${ }^{19}$ The preimplementation sample had more patients with stroke. Their relatives and carers were more involved with assisting and feeding than families of patients without stroke at that time $(\mathrm{p}<0.015)$; numbers in the later group may have been too small to demonstrate this.

\section{Guideline COMPLiance}

Key staff activities improved after guideline implementation:

- 9\% more patients had swallowing function screened within first 24 hours $(53 \% v 62 \%)(\mathrm{p}<0.001){ }^{20}$

- More patients were screened for dysphagia using a validated screening tool ( 0 v 32\%).

- There was a $17 \%$ increase in screening for nutritional risk using a valid tool within 24 hours of admission $(1 \% v 18 \%, \mathrm{p}<0.001)$.

- There was a $23 \%$ increase in the use of a validated nutrition risk tool for screening within the first week $(3 \% v 26 \%)$ and a $20 \%$ increase in the use of a validated tool for monitoring nutritional status $(17 \%$ v 37\%), (both $\mathrm{p}<0.001$ ).

- Targeted referrals to physiotherapists and occupational therapists increased (physiotherapy referrals for patients with postural and arm impairments increased from $61-63 \%$ to 91-92\%; occupational therapy referrals for patients with eating related disabilities increased from $58-70 \%$ to $82-84 \%$; all $\mathrm{p}<0.001)$.

- There was an $11 \%$ reduction in the number of patients for whom nutrition support decision making was deferred beyond 5 days of admission $(17 \% v 6 \%, \mathrm{p}<0.001)$. 
- Similar numbers of patients were tube fed (16\% v 13\%), but with changes to commercial tube contracts and insertion and checking procedures, use of feeding tubes was reduced from a median 3.5 to 2 new tubes per patient $(\mathrm{p}<0.05)$, and use of $\mathrm{x}$ rays was reduced by $50 \%$, from a median 2 per tube fed patient to $1(\mathrm{p}<0.019)$. There was a $30 \%$ increase in tube feedings implemented and established as prescribed (ie, recorded delivery of $\geq 50 \%$ of prescriptions) ( $51 \% v 81 \%, \mathrm{p}<0.016)$.

Non-significant improvements were seen in assessment and referral to SLTs. ${ }^{20}$ Of 77 and 75 dysphagic patients in pre- and post-guideline groups, respectively, $87 \%$ and $91 \%$ were referred to SLT. Of these referrals, $64 \%$ and $68 \%$ were passed to SLTs on the day of or day after screening, with $22 \%$ and $42 \%$ of referred patients assessed within 2 working days of receipt of referral, and $39 \%$ and $56 \%$ assessed within 72 hours of admission. ${ }^{21}$

More patients were weighed $(29 \%$ v 33\% weighed within the first 5 days, 30\% $v 35 \%$ weighed more than once for nutritional monitoring, $\mathrm{p}<0.4$ ). Quantities of feed delivered by nasogastric tube more closely matched feed prescriptions (recorded delivery of mean volumes $50 \% v 66 \%$ of dietetic prescription, from insertion of first to withdrawal of final tube). Few gastrostomy tubes were placed $(7 v 10)$ with similar durations (mean 33 and 26 days from admission).

\section{Patient outcomes}

Several patient outcomes improved. When swallowing problems were suspected, time spent without nutrition from admission awaiting assessment to management decreased from a mean of 9 to 3.7 days $(\mathrm{p}<0.001)$. Total time spent without nutrition, allowing that nutrition support was often interspersed with further periods of starvation, decreased from a mean of 10.2 to 4.7 days $(\mathrm{p}<0.001) .{ }^{20}$ These analyses excluded patients for whom nutrition support was recorded as inappropriate and only counted whole days.

Fewer patients in the post-implementation group had episodes of chest infection, aspiration pneumonia, and/or sepsis of unknown origin (33 patients with 46 episodes $v 13$ patients with 18 episodes in the post-implementation group), and there were fewer episodes overall (both $\mathrm{p}<0.003$ ). ${ }^{20}$

In the limited subsamples of patients and carers interviewed before discharge, reported experiences of nutrition management were similar and predominantly positive at both time points although expectations varied widely. Respondents may have been reluctant to criticise hospital treatment because of their recent dependence on it.

\section{Costs}

Costing information was supplied to the external evaluation team, and a cost effectiveness analysis was done with length of stay and bed occupancy as the outcomes of interest. ${ }^{1}$ Pre- and post-implementation groups did not differ for length of stay. Many factors influence length of hospital stay of predominantly elderly and dependent patients. ${ }^{22}$ The beneficial outcomes occurred primarily in a subgroup of patients with dysphagia, and numbers may have been too small to show statistical significance. A similar study showed that mean length of stay for patients who develop chest infections was about double that of those who did not. ${ }^{23}$ Applying this estimate to the infection data from this study would reduce the mean length of stay by about 1.5 days. Based on this hospital's admission data, this equates to 900 bed days/year. Estimated annual savings of approximately $£ 90000$ were associated with these bed days/year saved by fewer infections during the project intervention. Other savings accrued from fewer chest $x$ rays and fewer drug prescriptions to treat the infections. These savings were offset by the additional
Table 3 Meal observations, guideline compliance, and patient outcomes in patients with stroke before and after guideline implementation

\begin{tabular}{|c|c|c|c|}
\hline Outcomes & $\begin{array}{l}\text { Before } \\
\text { n (\%) }\end{array}$ & $\begin{array}{l}\text { After } \\
\text { n (\%) }\end{array}$ & Significance \\
\hline \multicolumn{4}{|l|}{$\begin{array}{l}\text { Meal observations } \\
\text { ( } n=120,42 \text { stroke patients) }\end{array}$} \\
\hline Eat independently & $39(32)$ & $13(31)$ & \\
\hline Need assistance to eat & $48(40)$ & $17(40)$ & \\
\hline Need feeding & $18(15)$ & $9(21)$ & \\
\hline Tube fed & $8(7)$ & $3(7)$ & NS† \\
\hline Assisted to eat by relatives & $5(4)^{\star}$ & $2(5)^{\star}$ & \\
\hline Fed by relatives & $8(7)^{*}$ & $1(2)^{\star}$ & NS† \\
\hline \multicolumn{4}{|c|}{$\begin{array}{l}\text { Guideline compliance } \\
\text { ( } n=200 \text { before, } n=200 \text { after, all stroke patients) }\end{array}$} \\
\hline Swallowing function screened within 24 hours & $106(53)$ & $123(62)$ & $<0.001$ \\
\hline Screened for dysphagia using validated tool & 0 & $64(32)$ & $<0.001$ \\
\hline Screened for nutritional risk within 24 hours & $3(1)$ & $36(18)$ & $<0.001$ \\
\hline Use of validated nutrition risk tool for screening & $6(3)$ & $53(26)$ & $<0.001$ \\
\hline Use of validated nutrition risk tool for monitoring & $35(17)$ & $74(37)$ & $<0.001$ \\
\hline Referrals to physiotherapy $\ddagger$ & $61-63 \%$ & $91-92 \%$ & $\mathrm{p}<0.001$ \\
\hline Referrals to occupational therapy $\ddagger$ & $58-70 \%$ & $82-84 \%$ & $\mathrm{p}<0.001$ \\
\hline $\begin{array}{l}\text { Nutritional support decision making deferred } \\
\text { beyond day } 5\end{array}$ & $35(17)$ & $12(6)$ & $<0.001$ \\
\hline Tube fed & $33(16)$ & $27(13)$ & NS \\
\hline $\begin{array}{l}\text { Tube feeding implemented and established } \\
\text { ( }>50 \% \text { prescription delivered) }\end{array}$ & $17 / 33(51)$ & $22 / 27(81)$ & $<0.016$ \\
\hline Referral to SLT & $74(37)$ & $80(40)$ & NS \\
\hline Weighed within first 5 days & $58(29)$ & $66(33)$ & NS \\
\hline \multicolumn{4}{|l|}{ Patient outcomes } \\
\hline Chest infection, aspiration pneumonia, or sepsis & $33(16)$ & $13(6)$ & $<0.003$ \\
\hline
\end{tabular}

${ }^{*}$ Calculated using chi square test unless otherwise indicated; NS = not significant

† Mann-Whitney U-test

$\ddagger$ Calculated from numbers of patients with specific impairments that affect eating and treated with occupational therapy and physical therapy.

costs of the project: the cost of training and nurses' time (estimated at £6912) and the project coordinator’s salary. These latter costs were offset by reductions in physician time required for these interventions. It was concluded that substantial net savings had accrued.

\section{Discussion}

Stroke related eating disabilities and subsequent levels of eating dependency (table 3) were consistent with limited data available from previous studies ${ }^{410}$ and highlighted the importance of this topic in relation to nursing workload. The period in which this project occurred was characterised by intense pressure throughout the NHS, combining unprecedented staffing shortages, a near epidemic of flu, and winter bed pressures. With time scales dictated by external milestones, in a relatively short implementation period, staff compliance with guidelines was less than $100 \%$.

Some outcomes, such as length of stay and functional improvement are difficult to change, as they are influenced by several factors, such as stroke severity and availability of domiciliary support. ${ }^{22}$ Other outcomes may have been affected by the manner of implementation. Nutrition risk screening, for example, had been unsuccessfully addressed using the same tool 18 months before the project. Few wards used it, but those that did wished to retain it. A decision was made to relaunch this tool. However, rather than capitalising on existing knowledge, this may have been tainted by previous failure. It may be easier to generate enthusiasm for new initiatives. ${ }^{1}$ Nurse swallowing screening and referral, by contrast, was well received, albeit selectively used. ${ }^{25}$ This topic was originally highlighted during extensive grass roots discussions, in which opinion leaders of the professions were involved in the choice of screening tool, and role modelled and championed its use. Edu- 
cational sessions were accommodated within existing continuing professional development structures to enable explicit identification with professional development and role "norms." The scientific merits of the new tool were stressed, and problems of previous methods were highlighted through feedback of pre-intervention results. Reminders for new practices were built into professional documentation. Existing organisational structures were used where possible. Procedures changed to support new practices included enabling nurses to fulfil a new role (screening) and requiring screening completion for a nurse to access clinical assessment for patients. Combining multiple approaches appeared effective. ${ }^{14}$

Compliance with 18 of 24 guidelines could be compared before and after implementation; missing data from multidisciplinary documentation precluded full evaluation. In total, 15 analyses evaluating compliance with 11 guidelines showed significant $(\mathrm{p}<0.05)$ and meaningful improvement, although it is difficult to evaluate the extent to which changes in outcomes are the direct result of project activities. Firstly, the project must be regarded as a complete package intervention; changes cannot be attributed to individual components. For example, better targeted referral to therapists probably derived from heightened awareness of stroke patients and their problems because of project related information disseminated through all professional groups. Secondly, although the Trust undertook not to make substantial changes that could directly affect project activities, peripheral developments occurred. Non-project potential influences on project activities and outcomes were difficult to quantify. Nonetheless, shifts in favour of evidence-based practices occurred in tandem with patient benefits. For example, reductions in time spent without food and the incidence of nosocomial chest infections suggested enhanced nutritional support accompanied by improved outcomes.

\section{Conclusion}

Overall, the project showed that despite limited resources and a challenging healthcare climate, changes in practice can be made and supported by evidence-based guidelines. A randomised trial was neither a feasible nor ethically acceptable option for this study. Thus, we cannot rule out the possibility of non-project influences on outcomes or directly attribute changes in outcomes to compliance with the evidence-based guidelines. Nevertheless, beneficial outcomes were shown over the course of the study. Overall, the study contributes to the understanding of implementation of evidence-based practice in healthcare environments.

$$
\begin{array}{r}
\text { LIN PERRY, RGN, RNT, PhD } \\
\text { Mayday Healthcare NHS Trust and } \\
\text { Faculty of Health and Social Care Sciences } \\
\text { Kingston upon Thames, UK } \\
\text { Kingston University / St George's Hospital Medical School } \\
\text { SUSAN MCLAREN, RGN, PhD } \\
\text { Faculty of Health and Social Care Sciences } \\
\text { Kingston University / St George's Hospital Medical School } \\
\text { Kingston upon Thames, UK }
\end{array}
$$

1 Redfern S, Christian S, Murrells T, et al. Evaluation of change in practice: South Thames Evidence-based Practice Project (STEP). London: King's College, 2000. http://www.healthcare.ac.uk/fhscs/research/4a_step.htm http:// www.kcl.ac.uk/ip/gianbrown/PDFs/stepexecf.pdf

2 Ross F, McLaren S. An overview of aims, methods and cross-case analysis of nine implementation projects. South Thames Evidence-based Practice Project. London: St George's Hospital Medical School and Kingston University, 2000.

3 Bonita R. Epidemiology of stroke. Lancet 1992;339:342-4.

4 McLaren SM, Dickerson JW. Measurement of eating disability in an acute stroke population. Clinical Effectiveness in Nursing 2000;4:109-20.

5 Lennard-Jones JE. A positive approach to nutrition as treatment. London: King's Fund Centre, 1992. http://www.bapen.org.uk/pdfs/publications/ kings_fund.pdf

6 Davalos A, Ricart W, Gonzalez-Huix F,et al. Effect of malnutrition after acute stroke on clinical outcome. Stroke 1996;27:1028-32.

7 Gariballa SE, Parker SG, Taub N, et al. Nutritional status of hospitalized acute stroke patients. Br J Nutr 1998;79:481-7.

8 Finestone HM, Greene-Finestone LS, Wilson ES, et al. Malnutrition in stroke patients on the rehabilitation service and at follow-up: prevalence and predictors. Arch Phys Med Rehabil 1995;76:310-6.

9 Gariballa SE, Parker SG, Taub N, et al. Influence of nutritional status on clinical outcome after acute stroke. Am J Clin Nutr 1998;68:275-81.

10 Finestone HM, Greene-Finestone LS, Wilson ES, et al. Prolonged length of tay and reduced functional improvement rate in malnourished stroke rehabilitation patients. Arch Phys Med Rehabil 1996;77:340-5.

11 NHS Centre for Reviews and Dissemination. Undertaking systematic reviews of research on effectiveness. CRD Report Number 4. University of York: NHS Centre for Reviews and Dissemination, 1996. http://www.york.ac.uk/inst/ $\mathrm{crd} /$ report 4 .htm

12 Perry L, Love CP. Screening for dysphagia and aspiration in acute stroke: a systematic review. Dysphagia 2001;16:7-18.

13 Agency for Health Care Policy and Research. Acute pain management:operaive or medical procedures and trauma. Clinical Practice Guideline No1. AHCPR Pub 92-0023:1992. http://hstat.nlm.nih.gov/hq/Hquest/db/3102/ screen/DocTitle/odas/1/s/61271

14 NHS Centre for Reviews and Dissemination. Getting evidence into practice. Effective Health Care 1999;5. http://www.york.ac.uk/inst/crd/ ehc51.htm

15 Perry L. Implementing best evidence in clinical practice. In Craig JV, Smyth RL, editors. The evidence-based practice manual for nurses. Edinburgh: RL, editors. The evidence-based practic
Churchill Livingstone, 2002:240-73.

16 Perry L, McLaren S, Bennett M. Nutritional support for patients with acute stroke. The South Thames Evidence-based Practice Project. London: St George's Hospital Medical School and Kingston University, 2000. http:// www.healthcare.ac.uk/fhscs/research/word_documents/step/ nutritional $\% 20 \_$support.doc

17 Goldstein LB, Samsa GP. Reliability of the National Institutes of Health Stroke Scale. Extension to non-neurologists in the context of a clinical trial. Stroke 1997;28:307-10.

18 McLaren S, Dickerson JW, Wright J. Nursing support offered to stroke patients at mealtimes: a direct non-participant observation study. Proc Nutr oc 1997;56:255

19 Perry L. Eating after stroke: natural history and investigation of an evidence-based intervention. Doctoral dissertation. London: University of London, 2002.

20 Perry L, McLaren S. An evaluation of implementation for evidence-based guidelines for dysphagia screening and assessment following acute stroke: phase 2 of an evidence-based practice project. Journal of Clinical Excellence 2000;2:147-56.

21 Intercollegiate Working Party for Stroke. National Clinical Guidelines for Stroke. London: Royal College of Physicians, 2002. http:// www.rcplondon.ac.uk/pubs/books/stroke/index.htm.

22 Tierney A, editor. Discharge of patients from hospital. Report of a survey of current practice in acute hospital wards throughout Scotland and concurrent national surveys of community nursing staff and general practitioners relating to the discharge of patients from hospital (with particular reference to elderly patients. Edinburgh: University of Edinburgh, 1993.

23 Boyce JM, Potter-Bynoe G, Dziobek L, et al. Nosocomial pneumonia in Medicare patients. Hospital costs and reimbursement patterns under the prospective payment system. Arch Intern Med 1991;151:1109-14.

24 Counsell C, Dennis M. Systematic review of prognostic models in patients with acute stroke. Cerebrovasc Dis 2001;12:159-70.

25 Perry L. Screening swallowing function of patients with acute stroke. Part two: detailed evaluation of the tool used by nurses. I Clin Nurs 2001;10:474-81 